\title{
PEDRO PAULO ABREU fUnARI E O ESTUdo DA ANTIGUIDADE
}

Hector Benoit ${ }^{1}$

Pedro Paulo Funari, Professor Titular da Unicamp, possui uma produção tão extensa e de tal qualidade que seria inútil, da minha parte, aqui, procurar recorda-la em sua totalidade. Para constatar tal afirmação, basta ler o resumo do seu currículo na Plataforma Lattes. Nesse sentido, procurarei me deter aqui mais nas relações acadêmicas que nós compartilhamos durante mais de duas décadas, sendo ambos docentes do Instituto de Filosofia e Ciências Humanas da Universidade Estadual de Campinas, ele pertencendo ao Departamento de História e eu ao Departamento de Filosofia do mesmo Instituto.

Vim a conhece-lo no início dos anos 90, quando participamos do primeiro Conselho Editorial da Revista Ideias, publicação até hoje existente, que congrega a produção teórica dos diversos departamentos do IFCH. Já então, notei a sua extraordinária competência e habilidade acadêmica, ressaltando algumas das suas qualidades que o acompanharam sempre durante toda a nossa longa convivência: pontualidade e assiduidade nas reuniões, pareceres sempre cuidadosos, assim como cordialidade nas discussões, sem deixar de marcar com firmeza suas posições.

Em fevereiro de 1995, a partir da iniciativa do Diretor do IFCH, João Quartim de Moraes, a Congregação do IFCH decretou a criação dos Centros Internos de Pesquisa e Documentação. Entre os diversos centros de pesquisa então criados, surgiu o CPA (Centro do Pensamento Antigo Clássico, Helenístico e sua Posteridade Histórica). Inicialmente, foi uma iniciativa de diversos professores do Departamento de Filosofia. Lembro os nomes do próprio João Quartim de Moraes (com interesse maior no materialismo moderno e antigo, nesse sentido, nas obras de Demócrito e Epicuro), Francisco Benjamin de Souza Netto (especialista em Filosofia Medieval, mas, evidentemente grande conhecedor de Aristóteles e

\footnotetext{
1 Professor Livre-Docente, Universidade Estadual de Campinas, Campinas, Brasil. Email: hbenoit@uol.com.br
} 
Platão), Carlos Arthur Ribeiro do Nascimento (também especialista em Filosofia Medieval, porém, obviamente, também grande conhecedor do pensamento antigo clássico) e eu próprio, especialista em Platão e no platonismo, particularmente, com interesse no pensamento antigo e a dialética em relação com a sua posteridade histórica.

A inspiração da minha parte para a criação do CPA, com essas características de estudar a Antiguidade, porém, veio do meu estágio em 1993 no Centre Louis Gernet, então dirigido por Jean-Pierre Vernant, que trabalhava em estreita colaboração com Pierre Vidal-Naquet, com o qual tive mais contato. Vidal-Naquet havia publicado, já há algum tempo, Le chasseur noir, e depois La démocratie grecque vue d'ailleurs. Impressionoume muito em suas análises como demonstrava o uso da Antiguidade em diversas épocas, na verdade, as mais diversas utilizações ideológicas da democracia grega ocorreram em diversos momentos. Vidal-Naquet mostra sobretudo como de diversas formas surgiram imagens da democracia grega, por exemplo, na Revolução Francesa, imagens que variavam de acordo com as posições políticas daqueles que as instrumentalizavam.

Assim, antes da fundação do CPA, na elaboração do seu projeto inicial percebemos o interesse teórico importante que teríamos na contribuição de especialistas em História Antiga e Arqueologia. $O$ nome então lembrado foi, imediatamente, aquele do professor Pedro Paulo Abreu Funari do Departamento de História do IFCH, que, convidado, aceitou participar da empreitada, assumindo o cargo de Diretor-Adjunto. Tendo eu próprio assumido, inicialmente, o cargo de Diretor do CPA. Pedro Paulo, apesar de se dedicar à História Antiga e à Arqueologia, também partilhava dessa necessidade de pensar o passado também do ponto de vista da sua utilização no presente.

Já em 1995, Pedro Paulo Funari e eu próprio passamos a organizar mais ativamente as realizações do CPA. Nesse ano, foi efetuado o I Colóquio do CPA no IFCH e como passou a ser o habitual durante diversos anos, desde esse primeiro colóquio, combinamos as atividades voltadas para História Antiga com aquelas de Filosofia Antiga, refletindo também sobre a posteridade destas áreas. Realizamos de lá para cá, mais de 20 colóquios, o próximo está agendado provisoriamente para maio de 2018. Reuniões mensais organizativas passaram a ser realizadas com os membros do centro e seminários com a participação de professores convidados de diversas universidades tanto nacionais como estrangeiras, sem deixar de envolver o trabalho cooperativo de alunos de Graduação e Pós-Graduação de ambos os Departamentos. Já em 1996 iniciamos a publicação do centro intitulada Boletim do CPA, publicação com uma 
periodicidade aproximadamente semestral, que atingiu 21 exemplares em 2005. A partir do número 22/23 (um número duplo), a publicação passou a se intitular Revista de Estudos Filosóficos e Históricos da Antiguidade, permanecendo a ser publicada até hoje. Entre as publicações que colaboramos, recordo também que Funari e eu próprio organizamos o livro Ética e Política na Antiguidade Clássica, Unicamp/FAPESP, 2001.

Lembro ainda da colaboração de alguns outros professores que participaram desde o começo do CPA, e ainda permanecem colaborando de suas atividades, ainda que não sejam professores do $\mathrm{IFCH}$, mas, possuem outros vínculos de pesquisa com a Unicamp: Maria Carolina Alves dos Santos (UNESP e hoje docente da Faculdade do Mosteiro de São Bento) e Gérson Pereira Filho (PUC-MG). Este último, está realizando pós-doutoramento atualmente comigo na Unicamp e estuda o diálogo As Leis de Platão, procurando pensar como alguns aspectos desse diálogo reapareceram na idade contemporânea. Entre os mais recentes colaboradores estão Robson Gabioneta, mestre em Filosofia Antiga pela Unicamp, e André de Góes Cressoni, doutor em Filosofia Antiga pela Unicamp e realizando atualmente pós-doutoramento sob a minha supervisão.

Fortalecendo as atividades do CPA, Funari e eu próprio estabelecemos relações também internas mais sólidas com o IEL (Instituto de Estudos da Linguagem), da Unicamp. Durante algum tempo, participou ativamente do CPA o professor Flávio Ribeiro de Oliveira, hoje Diretor do IEL. A professora Patrícia Prata do IEL, que exerceu inclusive a função de Diretora do CPA a partir de 2011 até recentemente. A professora também do IEL, Isabella Tardin Cardoso, que possui ampla atuação internacional, sendo pesquisadora convidada e professora do Seminar für Klassische Philologie de Heidelberg (Alemanha), também colaborou e colabora com o CPA.

Durante esses anos, vieram pouco a pouco a serem integrados diversos alunos, tendo participado alguns por um período mais longo, outros eventualmente, colaborando em seminários periódicos, contribuição nas publicações, e organização dos colóquios que inicialmente eram anuais, passando posteriormente, a ser mais extensos, em geral, três ou quatro dias, passando a ser realizados a cada dois anos. Entre os ex-alunos que tiveram grande participação lembro de Aparecido Gomes Leal que foi secretário organizativo do CPA por longo período, José Silva Lima secretário de redação nos primeiros tempos do Boletim do CPA (hoje Professor Associado UF do Acre), e muitos outros, que hoje são professores de destaque em outras universidades, como Ronildo Alves dos Santos (USP-RP), e Reinaldo Sampaio Pereira (UNESP). 
Entre os ex-alunos do professor Pedro Paulo Funari, hoje, docentes, destaco diversos que desde a Graduação colaboraram com as atividades do CPA, tais como Fábio A. Hering, hoje, Docente do Departamento de Museologia da UFOP-MG, Renata Senna Garraffoni, hoje docente de História na UFPR, ocupando funções de destaque nos estudos clássicos no Brasil; Glaydson José da Silva, hoje docente de História na UNIFESP, com ampla atividade editorial e também se destacando nacionalmente na área de História. Inclusive, Renata Garraffoni e Glaydson Silva participaram como organizadores do livro intitulado: Antiguidade como Presença: Antigos, Modernos e os Usos do Passado (2017). Porém, lembrar todos os professores e alunos que passaram pelo CPA a partir da vinculação com Funari, seria uma lista interminável. Basta dizer que ele supervisionou 17 pós-doutoramentos, orientou 35 doutoramentos e 42 mestrados.

Dos pesquisadores estrangeiros mais vinculados a Platão que pronunciaram conferências e outras atividades que estiveram no CPA, cito, entre outros: Nestor-Luís Cordero, professor da Université de Rennes I e pesquisador durante vários anos do Centre Leon Robin, Paris; Franco Tabasttoni, da Università degli Studi di Milano (Itália); Samuel Scolnicov da Hebrew University, Presidente da International Plato Society, 1998-2001; lembro também do presidente anterior da International Plato Society, Thomas M. Robinson, Professor Emeritus of Phylosophy and Classicacs at the University of Toronto. Estes dois últimos foram muito importantes para a criação da Sociedade Brasileira de Platonistas (SBP) que era centrada particularmente nos Colóquios do CPA e nos Encontros do GT Platão e Platonismo, vinculado à Anpof. Coordenei durante um bom tempo estas reuniões com a ajuda da professora Maura Iglésias (PUC-RJ), o professor Miguel Spinelli (UFSM-RS), o professor Fernando Muniz (UFF-RJ) e JAA Torrano (USP).

Mais tarde, com a colaboração do professor Pedro Paulo Funari, aproximou-se do CPA, o professor Gabriele Cornelli, inicialmente na Universidade Metodista, mais tarde, ingressando na UnB. A participação de Gabriele Cornelli no CPA foi então decisiva para impulsionar o crescimento da SBP, culminando com a eleição de Cornelli para presidente da International Plato Society (2013-2016), que realizou pela primeira vez o seu tradicional simpósio internacional em um país da América Latina, no Brasil, particularmente, em Brasília. Consagrando definitivamente o nosso país como uma referência internacional nos Estudos Clássicos.

Tudo isso somente foi possível aos amplos vínculos com os estudos clássicos internacionais que o CPA estabeleceu desde o seu começo, 
através dos seus diversos pesquisadores, colóquios, assim como publicações, e neste sentido, Pedro Paulo Funari contribuiu em grande parte, basta constatar a importância desse aspecto internacional na sua formação estabelecendo contatos sólidos com pesquisadores dos mais diversos países. Lembramos para isso alguns dados que constam no seu currículo e que resumem a sua formação complementar no exterior:

2013 - 2013 - Pós-Doutorado.

Stanford University, STANFORD, Estados Unidos. Bolsista do(a): Stanford University, SU, Estados Unidos.Grande área: Ciências Humanas

2009 - 2009 - Pós-Doutorado.

Stanford University, STANFORD, Estados Unidos. Bolsista do(a): Conselho Nacional de Desenvolvimento Científico e Tecnológico, Cnpq, Brasil.

Tecnológico, CNPq, Brasil. Grande área: Ciências Humanas Grande Área: Ciências Humanas / Área: Arqueologia. Grande Área: Ciências Humanas / Área: Arqueologia / Subárea: Arqueologia Histórica.

2009 - 2009 - Pós-Doutorado.

Durham University, DURHAM, Inglaterra. Bolsista do(a): Conselho Nacional de Desenvolvimento Científico e Tecnológico, CNPq, Brasil. Grande área: Ciências HumanasGrande Área: Ciências Humanas / Área: Arqueologia. Grande Área: Ciências Humanas / Área: Antropologia.

2008 - 2008 - Pós-Doutorado.

Université de Paris X, Nanterre, Paris X, França. Bolsista do(a): Conselho Nacional de Desenvolvimento Científico e Tecnológico, CNPq, Brasil. Grande área: Ciências HumanasGrande Área: Ciências Humanas / Área: Arqueologia. Grande Área: Ciências Humanas / Área: Arqueologia / Subárea: Arqueologia Histórica.

1998 - 1999 - Pós-Doutorado. 
Universitat de Barcelona, UB, Espanha. Bolsista do(a): Universidad de Barcelona, UB, Espanha. Grande área: Ciências HumanasGrande Área: Ciências Humanas / Área: Arqueologia / Subárea: Arqueologia Histórica. Grande Área: Ciências Humanas / Área: Arqueologia.

1996 - 1997 - Pós-Doutorado.

University College London, UCL, Grã-Bretanha. Bolsista do(a): World Archaeological Congress, WAC, Grã-Bretanha. Grande área: Ciências Humanas

Grande Área: Ciências Humanas / Área: Arqueologia / Subárea: Arqueologia Histórica.

1994 - 1995 - Pós-Doutorado.

Universitat de Barcelona, UB, Espanha. Grande área: Ciências Humanas Grande Área: Ciências Humanas / Área: Arqueologia / Subárea: Arqueologia Histórica. Grande Área: Ciências Humanas / Área: Arqueologia.

1992 - 1993 - Pós-Doutorado.

University College London, UCL, Grã-Bretanha. Bolsista do(a): World Archaeological Congress, WAC, Grã-Bretanha. Grande área: Ciências Humanas Grande Área: Ciências Humanas / Área: Arqueologia. Grande Área: Ciências Humanas / Área: Arqueologia / Subárea: Arqueologia Histórica.

1991 - 1992 - Pós-Doutorado.

Illinois State University, ILSU, Estados Unidos. Bolsista do(a): Illinois

State University, ISU, Estados Unidos. Grande área: Ciências Humanas

Grande Área: Ciências Humanas / Área: Arqueologia / Subárea: Arqueologia Histórica. 
1989 - 1989

Archaeological theory. University College London, UCL, Grã-Bretanha.

$1988-1988$

Arqueología de las ánforas romanas. Universidad de Barcelona, UB, Espanha.

$1988-1988$

Roman amphorae. University of Southampton, SOUTHAMPTON, Inglaterra.

1987 - 1987

Extensão universitária em Arqueologia de campo, em Arva. Universidad Complutense de Madrid, UCM, Espanha.

Diante de tudo isso acima mencionado a respeito da colaboração acadêmica de Pedro Paulo Funari, somente venho a juntar-me com aqueles que organizaram essa justíssima homenagem á sua obra, sobretudo, pois, como disse anteriormente, a sua contribuição aos estudos clássicos é vastíssima e excede em muito os poucos elementos por mim recordados neste texto. 